\title{
Where is prehospital care heading?
}

\author{
Malcolm Boyle PhD \\ Affiliations: \\ Editor, Australasian Journal of Paramedicine
}

\begin{abstract}
It was interesting to note a story in The Canberra Times on the $27^{\text {th }}$ January 2014 about paramedic interns in New South Wales (NSW) not being allowed access and use of basic life-saving drugs, such as adrenaline (1). An ambulance spokesperson stated that the interns could apply to undertake the training in drugs such as adrenaline whilst they are working in isolated areas. The statement by the ambulance spokesperson about people who have severe allergic reactions carrying their own Epipens ${ }^{\mathrm{TM}}$ is not always true and if they are unable to administer it themselves then what paramedic will have time to go looking through a person's belongings to look for it?
\end{abstract}

If school teachers in NSW can be educated about allergic reactions and anaphylaxis, including the use of the Epipen ${ }^{\mathrm{TM}}$ or Anapen ${ }^{\mathrm{TM}}$, then why can't the paramedic interns be taught before they start on road, plus be given an Epipen ${ }^{\mathrm{TM}}$ or Anapen ${ }^{\mathrm{TM}}$ to use if required? The cynic in me says "it's in the too hard basket" or the overall cost and the issue of educating the paramedic interns is one of the barriers.

In the case of allergic reaction/anaphylaxis management, the Australasian Society of Clinical Immunology and Allergy provide a website (www.allergy.org.au) that contains information for the layperson and health professionals about allergy and anaphylaxis, including various education packages and other useful information. The resource is available, someone in NSW ambulance just needs to make use of a "free" quality resource.

The Victorian paramedic enterprise bargaining exercise is still dawdling along, some of the statements raised during the process are interesting, like "being treated and paid as professionals". Well some of these paramedics may want to start acting like a professional before anyone considers them to be one. Many students come back from ambulance clinical placements with stories of poor treatment by paramedics, like, being told to "carry the bags and not to talk or touch the patient unless told to do so" and "your only here to observe not to do anything". Clinical placements are supposed to be an educational experience where the student consolidates the theory and classroom practice in the "real world". Some of these paramedics need to remember these students may be their new partner in a few months time. Even senior ambulance service management in Victoria need to see student clinical placements as an educational experience not a "socialisation exercise" as has been the case.

South Australia appears to be heading in the right direction with legislation to define what a paramedic is and what qualifications are needed. This is probably one component of the registration issue, which is still an ongoing saga. There is certainly enough evidence to justify national paramedic registration so we need to keep lobbying the politicians and community promoting the benefits of paramedic registration in Australasia.

Do we need extended care paramedics or do we need to look at the type of cases seen by Australian ambulance services and tailor the paramedic undergraduate courses to suit? This includes differentiating between metropolitan, rural and isolated location case types and consideration about local medical and paramedical resources. I think the outcome of the study into extended care paramedic use funded by HealthWorkforce Australia at five sites across Australia will be interesting when it is finally released (2).

The issue of paramedics being exposed to workplace violence appears to be on the increase across Australia with some of the more violent and noteworthy cases making the media. The workplace violence that does not make the media is that perpetrated by other paramedics, emergency service workers and healthcare providers. This violence occurs against paramedics in the workplace and university students undertaking clinical placements. There needs to be a better identification and reporting 
Boyle et al

mechanism that provides anonymity to the affected, a task that requires more work.

The future of prehospital care in Australia should be positive as it is one of the best systems

internationally, however, some of the ongoing and emerging issues are dulling the bright future.

\section{REFERENCES}

1. Robertson J. Ambos left without key drugs. The Canberra Times. 27th January 2014.

2. HealthWorkforce Australia. Extending the Role of Paramedics 2012 [22nd January 2014]. Available from:

http://www.hwa.gov.au/workprograms/workforce-innovation-andreform/extended-scopes-of-practiceproject/extending-role-of-paramedics. 